\title{
State-of-the-art of intelligent minimally invasive surgical robots
}

\author{
Masakatsu G. Fujie, Bo Zhang (ه) \\ Future Robotics Organization, Waseda University, Tokyo 1620044, Japan; Beijing Advanced Innovation Centre for Intelligent Robots and \\ Systems, Beijing Institute of Technology, Beijing 100081, China \\ (C) The Author(s) 2020. This article is published with open access at link.springer.com and journal.hep.com.cn
}

\begin{abstract}
A number of developed countries are rapidly turning into super-aged societies. Consequently, the demand for reduced surgical invasiveness and enhanced efficiency in the medical field has increased due to the need to reduce the physical burden on older patients and shorten their recovery period. Intelligent surgical robot systems offer high precision, high safety, and reduced invasiveness. This paper presents a review of current intelligent surgical robot systems. The history of robots and three types of intelligent surgical robots are discussed. The problems with current surgical robot systems are then analyzed. Several aspects that should be considered in designing new surgical systems are discussed in detail. The paper ends with a summary of the work and a discussion of future prospects for surgical robot development.
\end{abstract}

Keywords robot history; medical robot; surgical robot; radiofrequency ablation; organ model

\section{Introduction}

Personal robots have long been expected to be used in practical applications. However, this expectation has yet to materialize because of two factors. First, no actual market for such robots exists despite the society's growing need for them. Second, the required peripheral technology and maintenance of the social infrastructure are insufficient and do not allow robots to play an active role. For robots to operate effectively as partners to humans, they must be well integrated into parts of social systems. Appropriate preparations have been made in the 21 st century. A strong demand also exists for real robots to act as good human partners in many fields, including robot-assisted surgeries.

Most developed countries and a number of developing countries, such as China, are now facing the problem of aging populations [1-3]. Increasing numbers of elderly people mean a relative reduction in the number of available assistants. Health and security are the top concerns of developed countries with rapidly aging populations. The development of the industry required to achieve these health and security aims is considered promising. The development of specialized medical aid equipment has enabled bedridden patients, wheelchair users, and other

Received July 18, 2019; accepted December 18, 2019

Correspondence: Bo Zhang, zhangbo1982@aoni.waseda.jp types of patients to live independent and rewarding lives. The use of new surgical equipment also reduce pain and improve patients' subsequent quality of life.

The increase in the elderly population has expanded the market for robots, and much technological progress has been achieved in the past 30 years. Therefore, the potential use of medical robots in the future is promising. One specific branch of medical robotics, that is, surgical robotics, has undergone major development. Surgical robotics is expected to generate a huge market in the future. Given the complexity of the human body and the differences between individuals, along with the empirical differences between doctors, surgical robot systems are projected to act as partners to doctors to help them perform surgeries efficiently, safely, and easily. However, most current surgical robot/tool systems are simply tools for doctors. The robots are not aware of the surgical requirements or those of individual doctors. Ideal surgical systems should be able to deal with misoperations by surgeons and make appropriate suggestions to guide and support surgery. We define these ideal systems as intelligent surgical systems. These systems should serve as a powerful tool to help society deal with aging human populations.

The current study provides an overview of current intelligent surgical robots and focuses on three surgical systems with wide usage ranges. Providing a background description of the development of robot technology before 
discussing intelligent surgical systems is essential because the development of surgical robots is closely related to the overall development of the robotics industry. This paper is structured as follows. The second section introduces a concise history of robot development to provide readers with a rich overview. The third section discusses several of the main intelligent surgical robots. The technical characteristics, advantages, and disadvantages of these robots are also analyzed in detail. Based on the second and third sections, the fourth section proposes and analyzes the aspects that should be considered in the design of new surgical robotic systems. The final section details the conclusions drawn and future perspectives.

\section{Brief review of robot history}

Advances in robotics have led to innovations in surgical methods. The demand for medical applications has also promoted the overall advancement of robotics. Japan has long held a prominent position in the field of robotics research, particularly since 1970. Robots for industrial, medical, and life support applications have been widely developed and applied in Japan. Therefore, the introduction to robots in this work mainly stems from the perspective of the Japanese history of robotics. Fig. 1 shows the chronological development of robotic technology, which can be divided into 10 stages. Representative robots and associated developments at each stage are introduced in the following sections.

The period before 1940 is referred to as the Age of Old Dreams of Robots. The ancient Chinese Wooden Ox and Gliding Horse [4] and the mechanical doll from the
Japanese Edo era [5] can be regarded as the earliest prototypes of robots. Subsequently, robots were drawn in comics. The fully automatic Astro Boy and the semiautomatic and remote-controlled Ironman No. 28 were popular among the Japanese people during that time.

From 1940 to 1970, the enthusiasm for the use of robots in industrial applications ballooned. Industrial robot development became a task for companies and research institutes. Thereafter, American research institutions began to develop industrial robots. The Versatile Transfer Machine [6] and Unimate [7] are representative robots that were developed during this period.

The period from 1960 to 1970 is regarded as the cradle period of robot development. In 1964, Waseda University began to research machine-controlled prostheses $[8,9]$. Around the same time, US companies such as GE developed prototypes for the current power suits and mobile robots for military purposes $[10,11]$.

"The First Development Period" of Japanese robots took place from 1971 to 1975 . In addition to Unimate, which was popular among many companies in the 1960s, Hitachi also developed an automatic casting robot in 1975 [12]. The automatic casting robot was the first robot that could control the height of a runner surface using a visual sensor on the factory line.

The late 1970s saw further development of industrial robots. For example, SCARA [13,14], a horizontal multi joint assembly line robot that was developed by Professor Makino of Yamanashi University, was popular among many companies for its precision work. Meanwhile, the United States developed a vertical articulated robot called the PUMA $[15,16]$. Outside the industry, robots were also used in other fields. For example, Matsushita pioneered the

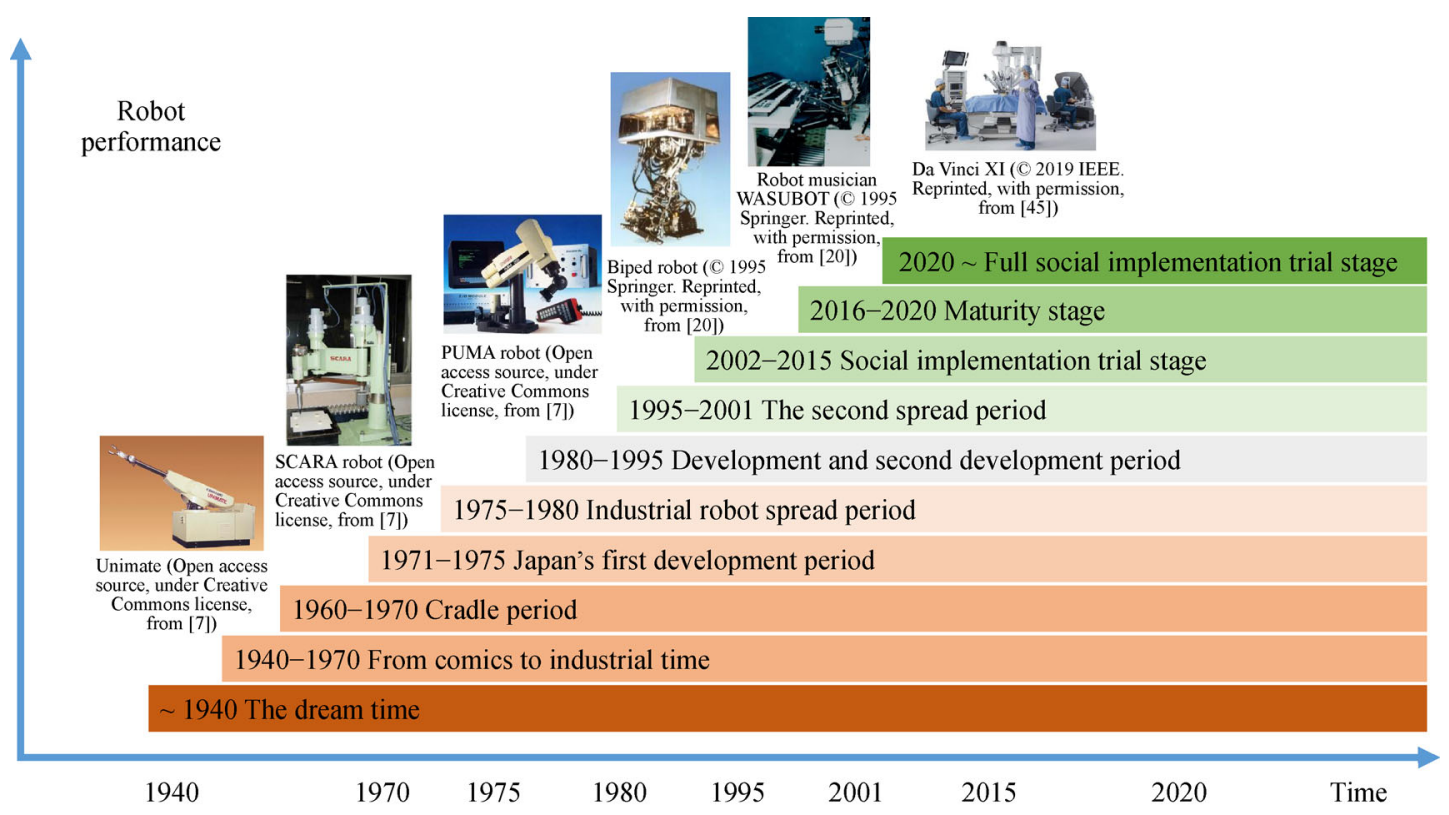

Fig. 1 History of robot development. 
development of a communication robot called Tama $[17,18]$ while Secom developed a food assistant robot named My Spoon [19].

The period from 1980 to 1995 is regarded as the second development period where Japanese companies competed in the development of various robots. Japanese companies presented a biped robot [20,21] and an automatic music playing robot $[22,23]$ at the Tsukuba Expo in 1985. The development of extreme working robots [24] for use in nuclear power plants led by the Ministry of International Trade and Industry, along with the development of cleaning robots that could be used in ordinary office spaces, was also noted during this time. During the same period, Carnegie Mellon University made progress in the development of autonomous vehicles, and their car crossed the US in 1995 [25]. In addition, agricultural robots were developed at Ohio State University [26]. At the same time, minimally invasive surgical robots received increasing research attention, and their development progressed. Minimally invasive surgery in the form of endoscopic management of upper urinary tract stones was first proposed and performed in the UK in 1985 [27]. More than 500 renal and ureteric calculi were removed using this method, and the high levels of success and low complication rates verified the superiority of such minimally invasive surgery. Since then, a variety of minimally invasive surgical tools and systems [28-31] have been developed worldwide.

The second spread period for Japanese robots ran from 1995 to 2001. Continuing technological development brought advances in robotics and led researchers to pursue efficient and safe medical services. However, at that time, robot-assisted surgery was based entirely on doctors' experience. Therefore, the development of intelligent surgical robot systems that could be used easily, regardless of doctors' skill level, then became a hot research topic. A result of this requirement was the da Vinci surgical auxiliary robot [32] that was launched in 2000. A year later, a remote transoceanic surgery was performed successfully using the ZEUS surgical robot system [33]. During this period, significant progress was also made in robot systems for application in other fields. A robot developed by Hitachi Ltd. was loaded into space via a space shuttle in 2000 to work on the International Space Station. From this time onward, the development of walking support robots for the elderly and home cleaning robots, such as the Roomba [34], became popular. With this background, the Joba [35] robot was developed by Panasonic in cooperation with the National Rehabilitation Center for the Disabled of Japan. However, because of its high cost, this robot did not become popular. At the same time, the RodeoBoy rehabilitation robot [36] made in China made progress in terms of popularization because of its high quality and low price.

Various types of robots were used in a range of fields during the period from 2002 to 2015. In Japan, teleoperation-type construction machines were developed and tested [37]. In the United States, Boston Dynamics made progress in developing the Big Dog [38] transport robot for the US Department of Defense. During this period, humanoid robots also became a focus of research and development. Professor Hiroshi Ishiguro developed a humanoid robot named the Geminoid HI [39], which resembled Professor Ishiguro, including his voice and head movement.

Japan's robotics technology has matured since 2016. The full-scale social implementation of robots is anticipated to begin after 2020 .

\section{Major types of intelligent surgical robots}

With the continued advancements in robotics, great strides have been made in the development of surgical robots since the end of the last century, particularly in some developed countries that are facing super-aged societies. At present, many different types of surgical robots and surgical equipment have been developed with the aim of reducing operational difficulty and improving the quality of surgery. Robot-assisted surgery using these devices involves opening one or a few holes in a patient's body and inserting the operating arm or arms into these holes to perform surgery. When compared with traditional open surgery, robot-assisted surgery results in low trauma and short recovery time. However, for surgeons, robot-assisted minimally invasive surgery often entails a steep learning curve because of the use of rigid or flexible but unstable instruments within an operating field that is only viewed indirectly via a monitor [40].

The ideal surgical robot should be smart enough to be a doctor's extended "arm" and exhibit flexible operability and controllability rather than simply being a scalpel in the doctor's hand. To achieve this goal, robot systems should have a certain "understanding" of the purpose of the surgery and necessary information about the surgery, including the surgical environment, planning, and key processes. The desired intelligent surgical robot systems are expected to identify a doctor's operations during surgery, improve the accuracy of cutting and stitching, and guide and plan the entire surgery.

At present, three main types of intelligent surgical robots have been widely reported or used: multiport laparoscopy robots (MPLRs), single-port laparoscopy robots (SPLRs), and robotic needle insertion systems (RNISs). In addition to these three main robot types, several special surgical systems for use in specific surgeries have been developed, and they include robot systems for brain tumor ablation [41] and invasive throat [42], eye [43], and nose [44] surgery.

The three main types of intelligent robot systems can be used in different fields and in various application scenarios. 
Their advantages and disadvantages are shown in Table 1 along with representative works associated with these systems. Specific information about these robots is provided in detail in the following sections.

\section{Multiport laparoscopy robots}

When compared with conventional laparoscopy-type surgical instruments, MPLRs provide doctors with improved surgical perspective (i.e., a 3D field of view), enhanced maneuverability (five degrees of freedom (DOFs) or more in a single arm) and great surgical safety (e.g., use of a hand shake filter).

At present, the most popular and widely used surgical robotic system is the da Vinci surgical system developed by Intuitive Surgical. After obtaining US Food and Drug Administration (FDA) approval for surgery of the digestive system on July 11, 2000 [32], the scope of recognition of the system was gradually extended to thoracoscopic (thoracic) surgery, assisted incision cardiac surgery, urology, gynecology, pediatric surgery, stomatology, and otolaryngology. The da Vinci surgical system consists of an interactive operating platform for the surgeon, a multifunctional operating bed, and a surgical table. The surgical table contains three robotic operating arms (with five DOFs, including a two-DOF wrist) and one endoscope clamping arm. The system uses a master-slave control method, meaning that the surgeon can control the arms from the interactive operating platform. The latest model is the da Vinci XI (Fig. 2A), which has a force feedback function to give the surgeon an enhanced sense of immersion [45]. The best surgical system in the world is da Vinci. However, the system suffers from some drawbacks. Determining whether the arm is in contact with an organ or with the patient's abdominal wall is difficult because of the system's limited field of view. Contact with an organ may cause organ damage, which would lead to serious medical problems. Another problem is that it is still necessary to open four holes in the patient's abdominal cavity to perform surgery. In some cases where the surgical operating space is small, the da Vinci Xi surgical system cannot be used.

Another surgical system that has been used clinically is the ZEUS surgical robot system [33]. ZEUS was designed to assist in surgery and was originally produced by the American robotics company Computer Motion. This surgical system obtained FDA approval in 2001. The system has three robotic arms that can be remotely controlled. The surgical system also uses the masterslave control method. In 2001, remote cholecystectomy surgery was successfully performed on a 68-year-old female patient in Strasbourg, France, by a surgeon in New York using the ZEUS surgical support robot system [46]. However, the development of the ZEUS system was discontinued in 2003 after Computer Motion merged with Intuitive Surgical. ZEUS suffers from the same limitations for surgery in small operating spaces, and its lack of an effective force feedback method reduces its operational immersion experience [33].

A great deal of research has been carried out in the surgical robotics field in many research institutes. Other multiport robot systems have also been developed and reported. One such system is the Microhand [47], which was developed at Tianjin University on the basis of a master-slave operation mode with a force feedback function. Vascular suture experiments on a $3 \mathrm{~mm}$ carotid artery and on a leg artery of a rabbit (1 mm diameter) have been performed successfully using this system. Another

Table 1 Advantages and disadvantages of the three main types of intelligent surgical robots

\begin{tabular}{|c|c|c|c|c|c|}
\hline Systems & Advantages & Disadvantages & Time & Scientist/Institution & Achievement \\
\hline \multirow[t]{4}{*}{ MPLRs } & Minimally invasive & Multiple wound openings & 2000 & Intuitive Surgical, Inc., USA & Da Vinci \\
\hline & High accuracy & Large operation space & 2001 & Computer Motion, USA & ZEUS \\
\hline & Short recovery period & Limited field of view & 2005 & Tianjin University, China & Microhand \\
\hline & High immersion & Collide with organ & 2018 & Deakin University, Australia & HeroSurg \\
\hline \multirow[t]{6}{*}{ SPLRs } & Minimally invasive & Limited field of view & 2010 & Waseda University, Japan & Dynamic vision field \\
\hline & High accuracy & Limited operation space & & & control \\
\hline & Short recovery period & Complex structural design & 2013 & Korea Advanced Institute of & Novel joint mechanism \\
\hline & Force feedback & Complex control system & & Science and Technology, Korea & \\
\hline & $\begin{array}{l}\text { High immersion } \\
\text { Smaller operation space }\end{array}$ & Collide with organ & 2016 & Intuitive Surgical, Inc., USA & Da Vinci SP \\
\hline & & & 2016 & Waseda University, Japan & Dexterous manipulator \\
\hline \multirow[t]{4}{*}{ RNISs } & Minimally invasive & Needle deformation & 2001 & The University of Tokyo, Japan & CT compatible \\
\hline & High accuracy & Human tissue deformation & 2006 & Waseda University, Japan & Liver insertion \\
\hline & Short recovery period & Complex control system & 2012 & Waseda University, Japan & Breast insertion \\
\hline & & model & 2019 & $\begin{array}{l}\text { Beijing Institute of Technology, } \\
\text { China }\end{array}$ & CVC insertion \\
\hline
\end{tabular}


A Multiport laparoscopy robot systems

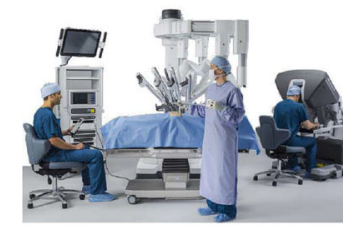

Da Vinci XI (C1995 IEEE. Reprinted, with permission, from [45])

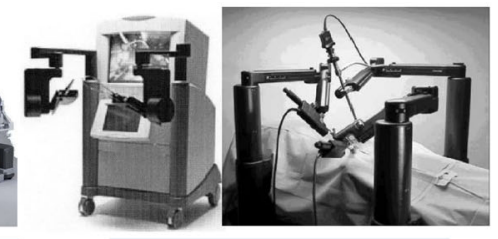

ZEUS (C2003 IEEE

Reprinted, with permission, from [46])

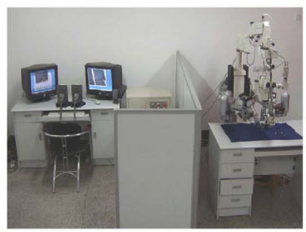

Microhand (C2005 IEEE Reprinted, with permission, from [47])

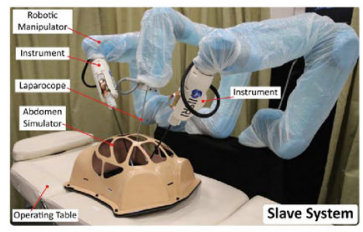

HeroSurg (C2018 IEEE

Reprinted, with permission, from [48])

B Single-port laparoscopy robot systems

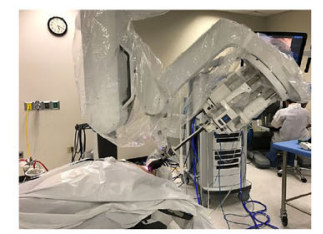

Da Vinci SP (C2019 Springer. Reprinted, with permission, from [50])

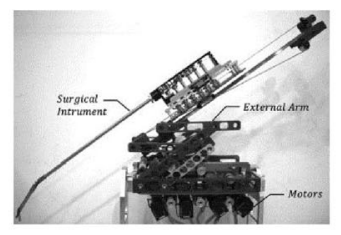

Single-port manipulator (C2013 IEEE. Reprinted, with permission, from [51])

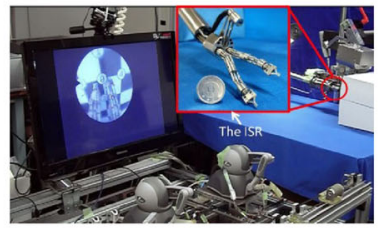

Single-port manipulator (C2013 IEEE. Reprinted, with permission, from [53])

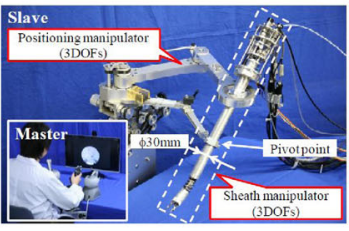

Single-port manipulator (C2011 IEEE. Reprinted, with permission, from [54])

C Robotic needle insertion manipulators

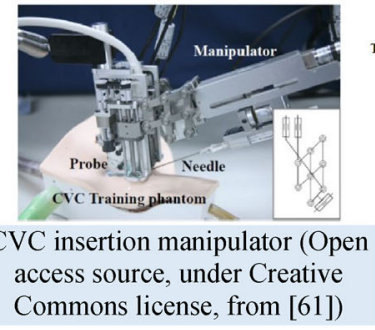

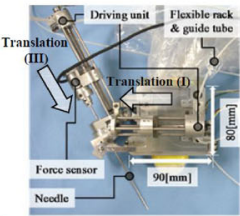

Liver insertion manipulator (C) 2009 IEEE. Reprinted, with permission, from [91])
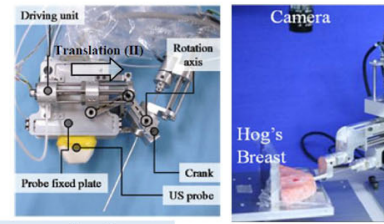

Commons license, from [61]

Fig. 2 Several major types of surgical robots.

representative system, the HeroSurg surgical robot system [48] developed at Harvard University, is characterized by a tactile feedback system that can detect a surgeon's operating force in real time.

MLPRs can be used to perform a variety of surgeries. However, for some of these surgeries, the operational space for the robot arms is small. Thus, access has been inconvenient or even impossible for robots with multiple arms. Other MLPRs, such as da Vinci, use multiple wound openings to perform surgery. Although this approach reduces patient trauma and enables short recovery times relative to traditional open surgery, it still needs improvement. A single-port surgical system can solve these problems effectively.

\section{Single-port laparoscopy robot}

A single-hole surgical robot only needs to open one hole in the human body to achieve the insertion of all instruments, including both endoscopic and robot arms, during an operation [49]. The use of a single hole relative to the multiport approach is characterized by minimal surgical space requirements, reduced trauma, and fast postoperative recovery periods. In addition, single-hole surgical robots use few surgical consumables, are low in cost, and are market-oriented. To make up for the deficiencies of the existing da Vinci surgical system in some applications, the da Vinci SP single-port surgical robot [50] was developed and is already being used in clinical practice. Other types of single-hole robot systems have also been reported [5159]; however, almost all of them are at the research and development stage and are still far from actual clinical use.

The main disadvantages of single-port technology are the inadequate size of the operating triangle, instrument crowding, and operation arm collisions [49]. Single-port laparoscopic surgery is limited by the number of holes used. The relatively concentrated placement of the instruments hinders the formation of an operation triangle. The instruments can interfere with one another. Thus, the operation and the surgical field of view are affected. Additionally, the concentricity of the instrument and the light source affect the depth and distance perceptions of the surgeon to a certain extent, thereby increasing the difficulty of performing the operation.

Current research is mainly focused on the design of the mechanical structure and improvement of the control method to solve existing problems and improve the clinical availability of single-port robot systems. Shin and Kwon [51] proposed a novel joint mechanism for single-port surgical systems. Their system had six DOFs that could 
avoid collisions between surgical tools and/or arms. The proposed structure can approach the surgical target more easily than conventional straight surgical tools. At the same time, this joint mechanism can prevent joint hysteresis and achieve accurate motion when using a large force. In another report [53], Liu et al. designed a dexterous manipulator (Fig. 2B). The device consists of three parts with a total of four DOFs: a linear motion joint (1-DOF), a bendable joint (2-DOF), and a rotational end effector (1-DOF). This manipulator is driven using a flexible shaft, and the end effector can perform bending motion in any direction. In single-port surgical robotassisted surgery, the field of vision is one of the most important factors affecting surgical outcomes. Sekiguchi et al. [54] developed a prototype surgical robot with a dynamic vision field control function. They used positioning (4-DOF) and sheath (2-DOF) manipulators for vision field control and dual tool tissue manipulators (gripping, 5DOF; cautery, 3-DOF) for surgery. Their vision control method combines "cut and vision field control" and "cut by vision field control" to enable fast surgery and improve the cutting accuracy.

Other current research is similar to the research described above and is intended to develop smart and safe mechanisms and convenient operating methods for single-port robot systems [57,59].

\section{Robotic needle insertion system}

Another type of intelligent surgical robot system is the RNIS. Unlike multiport and single-port robot systems, an RNIS inserts the required surgical tools into the target tissue to perform treatment directly. Thus, the smallest working incision is required. To reach the correct location and to conduct suitable treatments such as radio frequency ablation (RFA), the needle insertion system must solve the soft tissue deformation problem and understand the thermodynamic model of this tissue. Therefore, even with its lack of complex robot arms for operation by the surgeon, the robot system is still in high demand in terms of its design. Surgery assisted by an RNIS also offers important advantages with regard to reducing trauma and recovery time [60]. Percutaneous needle insertion has been widely used in central venous catheters (CVCs) [61] and in liver [62,63], lung [64], breast [65], and prostate surgeries $[66,67]$. With the rapid progress in medical devices and technology, increasing numbers of systems have been developed for use in percutaneous needle insertion surgery, as shown in Fig. $2 \mathrm{C}$.

The two main challenges that are encountered by researchers in the development of percutaneous surgery systems are needle trajectory control and appropriate treatment operation after the needle reaches the target area. Of these two challenges, precise needle trajectory control is the most basic issue to be resolved. The surgery is only likely to be successful if the needle can reach the correct location. The purpose of needle insertion is to prepare for surgical treatment, e.g., to conduct RFA or venous catheterization surgeries. To perform RFA well, the researcher must know and conduct research on the thermodynamic ablation model.

\section{Needle insertion guidance}

Medical devices that can generate images or video streams of the tissue to be inspected are used to guide the needle during the insertion process. These images or video streams allow the internal structure of the tissue to be observed, along with the spatial relationship between the needle and the tissue. At present, the most widely studied and used techniques for this purpose are computed tomography (CT), magnetic resonance (MR), and ultrasound (US) imaging [68-77]. Each method has its own advantages and disadvantages when used to guide needle insertion surgery.

CT technology uses computer-processed combinations of multiple X-ray measurements taken from different angles to produce cross-sectional images. A CT-guided needle insertion system should be used simultaneously with CT and therefore has several basic problems in surgical implementation. The first is the radiation problem faced by the patient and the doctor, both of whom are exposed to X-rays when $\mathrm{CT}$ is used to guide needle insertion in real time [78]. The second problem is that the surgical location must be fixed when using this system because the CT equipment is considerably large and must usually be placed in a separate room, but the needle insertion system still requires the cooperation of the CT equipment. The third difficulty is the limited size of the needle insertion manipulator and its operating space. A modern CT scanner has a bore with a diameter of approximately $60 \mathrm{~cm}$, and the body part of the patient to be examined must be located within this bore during the examination process. Therefore, in the design and operation processes of the needle insertion manipulator, this space limitation should be considered carefully [68]. The final problem is image artifacts. Some material requirements should be considered in designing the needle insertion device because metal produces artifacts during the CT scanning process [79]. However, in certain percutaneous surgeries, such as nerve blocks and facet joint injections, CT imaging has been widely accepted as the guidance modality; therefore, CT-guided needle insertion is still needed for some applications despite the aforementioned disadvantages [69].

MR-guided needle insertion systems have similar problems to CT in terms of work space, the operation space for the needle insertion manipulator, and material requirements [70]. Compared with CT, MR imaging 
(MRI)-guided needle insertion systems can provide better soft tissue contrast function, and neither the surgeon nor the patient need to worry about radiation damage [80]. Some materials [71,72], robot actuators [81,82], structures, and sensors $[83,84]$ have been developed to ensure their compatibility with MRI.

Relative to CT and MR-based systems, US-guided needle insertion systems offer maximum flexibility in terms of design and use as the typical US device is small and moveable. US-based systems are thus ideal for needle insertion guidance.

\section{Needle trajectory control}

To control the position and trajectory of the needle tip precisely during the puncture process, researchers have investigated several important process parameters. A number of them studied the relationship between the needle deflection force and the needle penetration depth and built a force-deflection model $[85,86]$. Their experimental results indicated that the moment and rotational force acting on the needle should also be considered in the force-deflection model. Other researchers also investigated the needle trajectory during the puncture process in soft tissue and found that the infinitesimal force per displacement is a useful parameter for online trajectory generation [87]. Multiple experimental results also showed that the bevel tip angle strongly affects needle deformation $[88,89]$ and that the introduction of a tissue model during needle insertion control will increase the accuracy of needle tip positioning [90].

\section{Discussion}

Most current surgical robotic systems and devices are still simply tools, and the success rate of surgical implementation depends on doctors' experience. Surgeons with limited experience find difficulty in using these systems because of individual differences and the lack of linearization of the human tissue model. In making surgical robots smart, the introduction of important information, such as the purpose of the surgery and the surgical environment, into surgical robot systems is necessary as such information enables these robots to correct any misoperation by doctors and provide appropriate suggestions at certain steps. Researchers should consider the following three aspects in introducing this information during the development of new surgical robot systems.

\section{Quantification of physical characteristics of the human body}

In the mechanical mechanics field, active research is now focused on small robots that can be inserted gently into a patient's body. From this stage, the control of robots operating in close contact with humans will be dependent on the mechanical information acquired from the "humanobject interaction" [91-94]. The basis for the acquisition of this information includes the mechanical mechanics, material mechanics, thermodynamics, and fluid dynamics. Regardless of the patient's race, age, gender, and the degree of their disease, the appropriate diagnosis and treatment should be performed by surgical robot systems. To achieve this goal, we need to express the biological model quantitatively and specifically. Surgical simulations must then be conducted in a virtual surgical environment using model reproduction technology to predict organ tissue deformation that might occur during operation. On the basis of the shape data of a patient's liver obtained from a preoperative diagnostic imaging system, a structural analysis method, such as the finite element method, can be used to construct a deformation model of the living body. At this stage, each parameter of the biological model can be set initially according to young healthy animal organs and then further corrected and improved using information from a database that stores various patient parameters using statistical processing $[95,96]$. In addition, boundary conditions are identified using image analysis or similar techniques from diagnostic images and are then set as the boundary conditions for the model. This type of method is called machine learning or deep learning. By performing simulations using the constructed model, searching for the optimum surgical insertion position and insertion angle is possible.

The construction of a biological model that can predict the deformation accurately based on material dynamics theory because the accuracy of deformation prediction during surgery is linked directly to the improvement of treatment accuracy. While many research groups have studied puncture plans, the evaluation models in many cases have been made from simple materials, such as silicon and gelatin [97-101]. However, the biological tissue to be modeled is complex and exhibits viscoelastic characteristics, which can be described using springs and dampers, and nonlinear stress and strain characteristics.

\section{Deformation model and heating cautery model of organ tissue}

The RFA technique has emerged as capable of reducing the physical and mental burden on patients because it does not require a large incision. This technique has been widely used to treat liver cancer by insertion of a needle into the cancerous tissue followed by the application of heat. However, when a needle is inserted into soft tissue such as the liver, the actual position of the cancerous tissue changes, thereby affecting the accuracy of the puncture. In addition, when cancerous tissue is cauterized by heating, the heat transfer process becomes complex because of 
differences in the distribution of the peripheral blood vessels. As a result, controlling the burning range quantitatively is difficult, and some cancer cells may be left untreated [102]. These findings indicate that actual biomaterials are required in data acquisition and validation experiments. A schematic illustrating the establishment of a liver model is shown in Fig. 3 .

If the organ tissue is simple, we can then use material mechanics as an approach for the numerical simulation of brain tumors. However, in recent years, the diagnosis and treatment of diseases in complex organs, e.g., breasts, prostate, lungs, heart, joints, blood vessels, and lymphatic vessels, along with newborns in the womb, have brought major challenges to medicine [103-105]. For breast cancer [103] patients, the softness of the breast tissue, the shape of the breast, and the location of the cancerous site during puncture treatment mean that the treatment effect is strongly influenced by the surgeon's experience. Therefore, the establishment of advanced diagnostic systems and topical treatment techniques to reduce the physical, cosmetic, and mental burdens on female patients is necessary (Fig. 4) [103]. In addition to establishing the accuracy of the puncture site, researchers have also constructed thermodynamic/hydrodynamic models of the liver to aid in the implementation of RFA procedures. Achieving the aim of killing cancer cells requires a reasonable supply of heat from the RFA needle. The relationship between the applied heat energy and the energy that must be absorbed by cancer cells must also be determined on the basis of thermodynamic theory. Blood flow also affects heat distribution. Thus, the effects of blood flow must also be considered when constructing a thermodynamic model of tissues and organs.

\section{Individual difference processing and control method}

Normal organ model-based preoperative trajectory generation, the intraoperative acupuncture insertion angle, and the intraoperative correction procedure are related to a patient's age, gender, medical history, daily environment, liver condition, and other factors. However, individual differences in liver stiffness and liver borders are not identifiable during the preoperative planning phase [106]. Modeling errors occur in pregenerated models because of individual differences between patients. Differences also exist between the behavior of model organs and the behavior of actual organs. Therefore, doctors can compare the information obtained during the surgery with their knowledge of organ characteristics obtained through experience. They can then perform treatment while applying the required intraoperative correction. For example, at the time of tissue puncture, the doctor recognizes the force transmitted to the liver by touch and performs the puncture procedure while estimating the hardness of the organ during the operation. To cope with the modeling errors caused by individual differences between patients, the computer analyzes the force information obtained during the operation via high-speed calculations and combines this information with the parameters of the biological model. Thus, a method is constructed to correct the boundary conditions of the model. In addition, the parameters and boundary conditions identified are used to enable the continuous correction of the insertion angle and the insertion position of the needle determined as part of the preoperative phase during the actual operation (Fig. 5) [106].

In addition to surgical robot systems, the individual
A

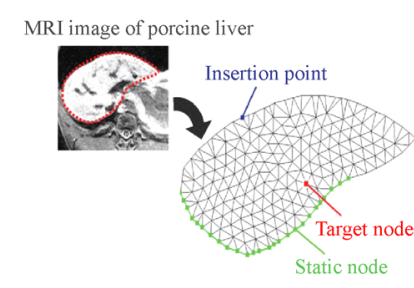

RI image of porcine liver

Deformation
simulator Simulation

Simulation

Needle

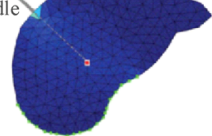

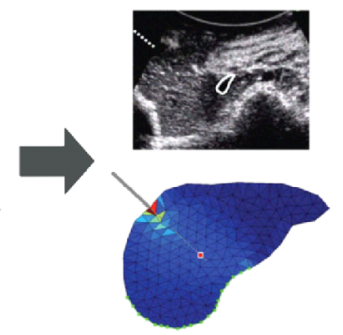

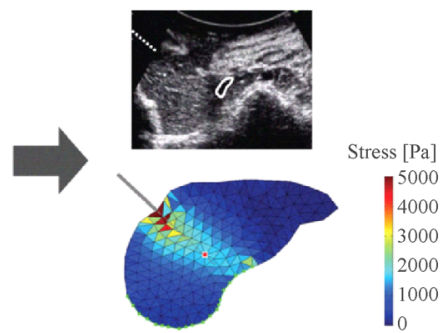

B
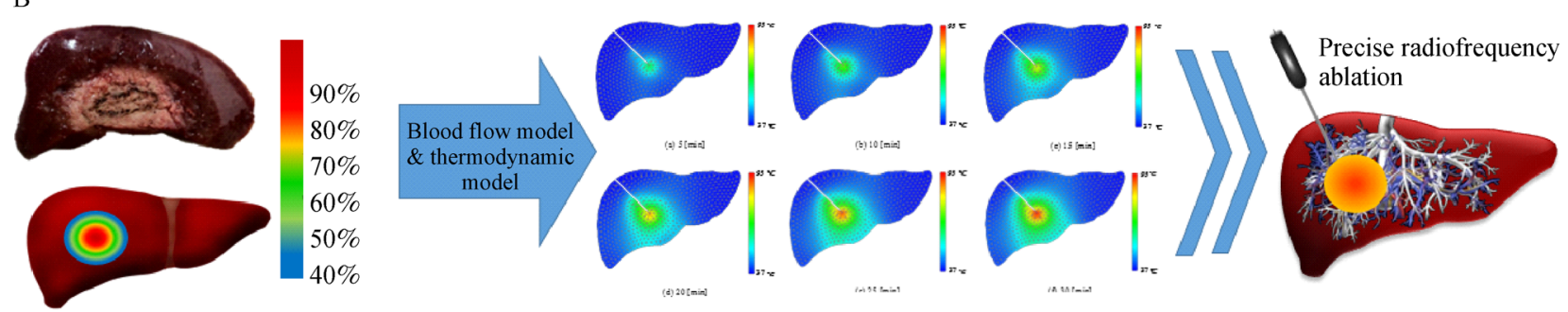

Fig. 3 Deformation model and heating cautery model of liver tissue. (A) Deformation of liver during needle insertion. (B) Temperature distribution of liver during tumor ablation. 


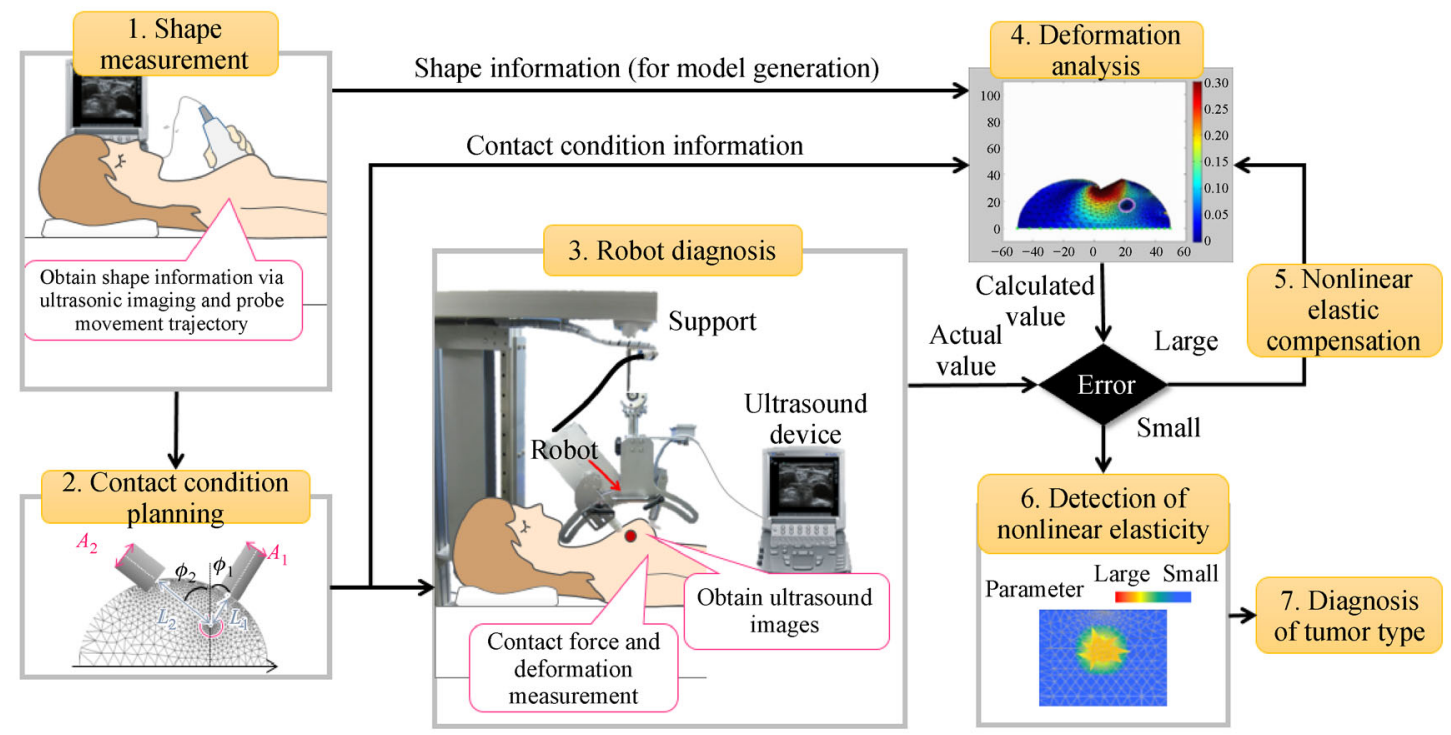

Fig. 4 Breast cancer diagnosis technology.

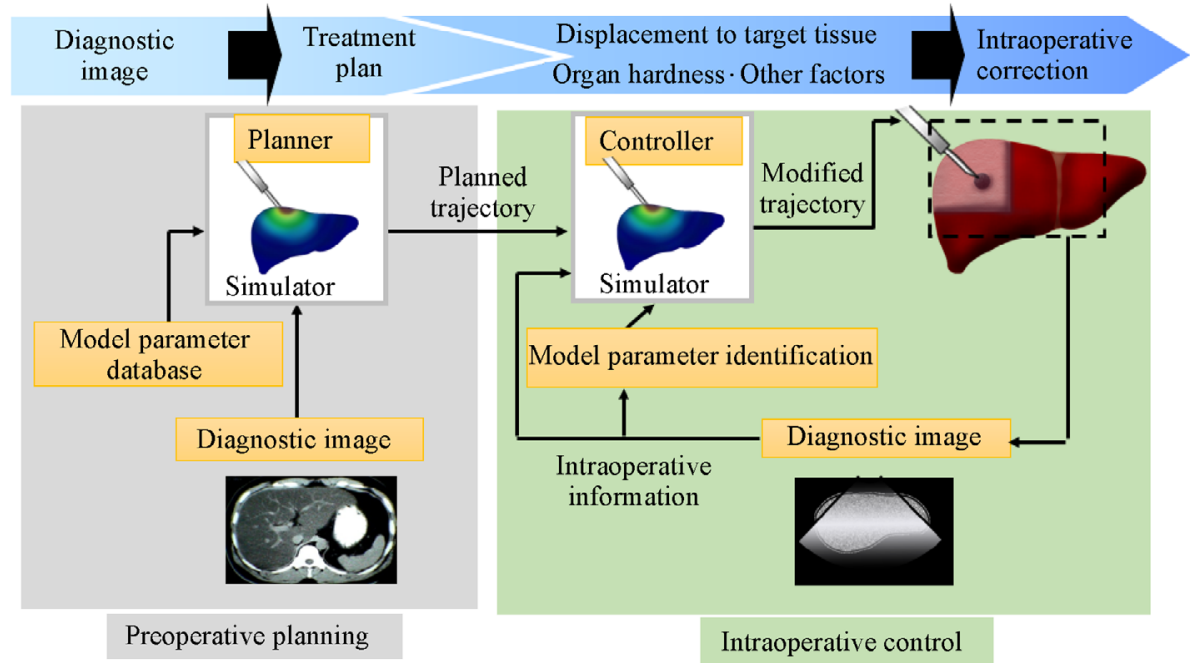

Fig. 5 Control method to handle individual differences. The difference between preoperative planed value calculated by the model and the actual value measured by the diagnostic device during surgery is repeatedly zeroed by convergence calculation (e.g., with a Karman filter).

differences between processing and control methods can be introduced to other medical robot systems, such as robot-assisted rehabilitation systems.

\section{Conclusions}

The problem of population aging is becoming an issue that most countries cannot avoid. A growing trend for robots to replace or assist humans in certain jobs exists. In the medical health field, intelligent surgical robots and other medical robots combine to form a line of defense for human health. While some surgical robot systems, such as the da Vinci system, have already entered clinical use, most surgical robots are still under development. New technologies and new treatments are projected to be introduced into surgical robot systems to bring great well-being to human patients.

The advantages and disadvantages of current surgical robot systems are apparent. These systems can be used to 
implement minimally invasive surgery to reduce patient pain and patient recovery time. However, with their limited field of view and operation space, surgical tools that protrude into patients may interfere with one another. In addition, the risk of contact between surgical instruments and other organs in a patient's body is also present. As a result of the complexity of the human body and the differences between individuals, robot systems and surgeons may be disturbed during surgery, and they may not always handle such disturbances well. Therefore, the incorporation of the entire surgical environment into the surgical decision-making process is necessary. We propose three aspects that could be introduced into the surgical process. Although these three aspects are closely related, each one is important and will be meaningful in improving the accuracy and reliability of robot-assisted surgery. Of the three aspects, the quantification of the physical characteristics of the human body serves as the foundation that provides preoperative planning information. The building of deformation models and heating cautery models of organ tissues can guarantee accuracy in minimally invasive surgery. Individual difference processing and control methods represent the final implementation, which ensures that robot-assisted surgery can be applied to any patient with high accuracy and reliability.

The technology of medical robotics is constantly improving. Other types of robots with great accuracy, efficiency, and flexibility have been reported, and they include cell-level minimally invasive surgical robots and soft robots [107-110], which may change the surgical approach in the future and benefit patients greatly. In the future, robotics will be widely applied in all aspects of life. We are committed to the use of mechanical engineering, materials mechanics, fluid mechanics, and thermodynamics to develop accurate and efficient surgical robots to cope with treatment of the elderly and improve the quality of life of surgical patients.

\section{Acknowledgements}

This work was supported in part by the National Natural Science Foundation of China and Shenzhen Robot Research Program (No. U1613221); in part by the National Key Research and Development Program (No. 2017YFC0110500); in part by the Global Centers of Excellence Program "Global Robot Academia," Waseda University, Tokyo, Japan; and in part by the Program for Leading Graduate Schools, "Graduate Program for Embodiment Informatics" of the Ministry of Education, Culture, Sports, Science and Technology.

\section{Compliance with ethics guidelines}

Masakatsu G. Fujie and Bo Zhang declare that they have no conflict of interest. This manuscript is a review article and does not involve a research protocol requiring approval by a relevant institutional review board or ethics committee.
Open Access This article is licensed under a Creative Commons Attribution 4.0 International License, which permits use, sharing, adaptation, distribution and reproduction in any medium or format, as long as you give appropriate credit to the original author(s) and the source, provide a link to the Creative Commons licence, and indicate if changes were made.

The images or other third party material in this article are included in the article's Creative Commons licence, unless indicated otherwise in a credit line to the material. If material is not included in the article's Creative Commons licence and your intended use is not permitted by statutory regulation or exceeds the permitted use, you will need to obtain permission directly from the copyright holder.

To view a copy of this licence, visit https://creativecommons.org/ licenses/by/4.0/.

\section{References}

1. Rowe JW, Kahn RL. Successful aging. Gerontologist 1997; 37(4): 433-440

2. Uhlenberg P. International Handbook of Population Aging. Springer 2009

3. Cavanaugh JC, Blanchard-Fields F. Adult Development and Aging. Cengage Learning 2017

4. Woods MB, Woods M. Ancient Transportation Technology: From Oars to Elephants. Twenty-First Century Books 2010: 48

5. Yokota Y. A historical overview of Japanese clocks and karakuri. In: Yan HS, Ceccarelli M. International Symposium on History of Machines and Mechanisms. Springer, Dordrecht. 2009: 175-188

6. Weston RH, Gascoigne JD, Sumpter CM. Intelligent interfaces for robots. Control Theory A 1985; 132(4): 168-173

7. Gasparetto A, Scalera L. A brief history of industrial robotics in the 20th century. Advances in Historical Studies 2019; 8: 24-35

8. Koganezawa K, Fujimoto H, Kato I. Multifunctional above-knee prosthesis for stairs' walking. Prosthet Orthot Int 1987; 11(3): 139145

9. Kato I. Trends in powered upper limb prostheses. Prosthet Orthot Int 1978; 2(2): 64-68

10. Tesar D. Where Is The Field of Robotics Going. Springer 1999: 112

11. Yang C, Zhang J, Chen Y, Dong Y, Zhang Y. A review of exoskeleton-type systems and their key technologies. Proc Inst Mech Eng, C J Mech Eng Sci 2008; 222(8): 1599-1612

12. Hartley J. New robot designs give increased production. Ind Rob 1980; 7(3): 186-188

13. Visioli A, Legnani G. On the trajectory tracking control of industrial SCARA robot manipulators. IEEE Trans Ind Electron 2002; 49(1): 224-232

14. Sprenger B, Kucera L, Mourad S. Balancing of an inverted pendulum with a SCARA robot. IEEE/ASME Trans Mechatron 1998; 3(2): 91-97

15. Tarn T, Bejczy A, Yun X. Coordinated control of two robot arms. IEEE Int Conf Robot Autom 1986: 468-473

16. Chimes P. Multiple-arm Robot Control Systems. Robotics Age 1985: 5-10

17. Taggart W, Turkle S, Kidd C. An interactive robot in a nursing 
home: preliminary remarks. CogSci Android Science Workshop 2005

18. Sugano S, Kato I. WABOT-2: Autonomous robot with dexterous finger-arm - finger-arm coordination control in keyboard performance. IEEE Int Conf Robot Autom 1987: 90-97

19. Abdulrazak B, Mokhtari M. Assistive robotics for independent living. The Engineering Handbook of Smart Technology for Aging, Disability, and Independence. 2008: 355-374

20. Takanishi A. In memoriam: Professor Ichiro Kato. Auton Robots 1995; 2(1): 7-10

21. Ichiryu $K$, Watanabe $H$, Nogami $T$, Nakamura I, Fujie $M$. Realization of biped robot by hydraulic drive. Proc JFPS Int Symp Fluid Power 1989: 421-428

22. Sugano S. Limb control of the robot musician 'WABOT-2'. Int Conf Adv Robotics 1985

23. Sugano S. Keyboard playing by an anthropomorphic robot. Theory and Practice of Robots and Manipulators (Fifth CISMIFToMM Symp) 1985

24. Sakakibara Y, Kan K, Hosoda Y, Hattori M, Fujie M. Low impact foot trajectory for a quadruped walking machine. JRSJ 1990: 662671

25. Pomerleau D. Alvinn: An autonomous land vehicle in a neural network. Adv Neural Inf Process Syst 1989: 305-313

26. Waldron KJ, McGhee RB. The mechanics of mobile robots. Robotics 1986; 2(2): 113-121

27. Payne SR, Ford TF, Wickham JEA. Endoscopic management of upper urinary tract stones. Br J Surg 1985; 72(10): 822-824

28. Hurteau R, DeSantis S, Begin E, Gagner M. Laparoscopic surgery assisted by a robotic cameraman: concept and experimental results. Proc IEEE Int Conf Robot Autom 1997: 2286-2289

29. Munro MG. Automated laparoscope positioner: preliminary experience. J Am Assoc Gynecol Laparosc 1993; 1(1): 67-70

30. Taylor R. Funda J, LaRose D, Trea M. A telerobotic system for augmentation of endoscopic surgery. IEEE Engineering in Medicine and Biology Society 1992: 1054-1056

31. Taylor R, Cutting C, Kim Y, Kalvin A, Larose D, Haddad B, Khoramabadi D, Noz M, Olyha R, Bruun N, Grimm D. A modelbased optimal planning and execution system with active sensing and passive manipulation for augmentation of human precision in computer-integrated surgery. Int Symp on Experimental Robotics 1991

32. Tewari A, Peabody J, Sarle R, Balakrishnan G, Hemal A, Shrivastava A, Menon M. Technique of da Vinci robot-assisted anatomic radical prostatectomy. Urology 2002; 60(4): 569-572

33. Masatoshi E, Seiji N. Robotic surgery assisted by the ZEUS system. Recent Advances in Endourology Endourooncology 2005: 39-48

34. Forlizzi J, DiSalvo C. Service robots in the domestic environment: a study of the Roomba vacuum in the home. Proc 1st ACM SIGCHI/SIGART Conf on Human-Robot Interaction 2006: 258265

35. Lee CW, Kim SG, Na SS. The effects of hippotherapy and a horse riding simulator on the balance of children with cerebral palsy. J Phys Ther Sci 2014; 26(3): 423-425

36. Seo DJ, Jun SW, Kim YO, Ko NY. Motion analysis for control of a 2-DOF horse riding robot. J Korea Robot Soc 2011; 6(3): 263-273

37. Hirabayashi T, Akizono J, Yamamoto $\mathrm{T}$, Sakai $\mathrm{H}$, Yano $\mathrm{H}$.
Teleoperation of construction machines with haptic information for underwater applications. Autom Construct 2006; 15(5): 563-570

38. Raibert M, Blankespoor K, Nelson G, Playter R. BigDog, the rough-terrain quadruped robot. IFAC Proc 2008; 41(2): 10822108525

39. Becker-Asano C, Ogawa K, Nishio S, Ishiguro H. Exploring the uncanny valley with Geminoid HI-1 in a real-world application. IADIS Int Conf Interfaces and Human Computer Interaction 2010: 121-128

40. Mack MJ. Minimally invasive and robotic surgery. JAMA 2001; 285(5): 568-572

41. Hu D, Gong Y, Hannaford B, Seibel EJ. Semi-autonomous simulated brain tumor ablation with RAVENII surgical robot using behavior tree. IEEE Int Conf Robot Autom 2015; 2015: 38683875

42. Remacle M, M N Prasad V, Lawson G, Plisson L, Bachy V, Van der Vorst S. Transoral robotic surgery (TORS) with the Medrobotics Flex ${ }^{\mathrm{TM}}$ System: first surgical application on humans. Eur Arch Otorhinolaryngol 2015; 272(6): 1451-1455

43. Havlena M, Maninis KK, Bouget D, Poorten EV, Gool LV. 3D reconstruction of the retinal surface for robot-assisted eye surgery. Computer Assisted Radiology and Surgery 2016: 112-113

44. Berthet-Rayne P, Leibrandt K, Gras G, Fraisse P, Yang GZ. Inverse kinematics control methods for redundant snakelike robot teleoperation during minimally invasive surgery. IEEE Robot Autom Lett 2018; 3(3): 2501-2508

45. Haidegger T. Autonomy for surgical robots: concepts and paradigms. IEEE Trans Med Robot Bionics 2019; 1(2): 65-76

46. Butner S, Ghodoussi M. Transforming a surgical robot for human telesurgery. IEEE Trans Robot Autom 2003; 19(5): 818-824

47. Wang SX, Ding JN, Yun JT, Li QZ, Han BP. A robotic system with force feedback for micro-surgery. IEEE Int Conf Robot Autom 2005: 200-205

48. Dalvand MM, Nahavandi S, Fielding F, Mullins J, Najdovski Z, Howe R. Modular instrument for a haptically-enabled robotic surgical system (HeroSurg). IEEE Access 2018; 6:2169-3536

49. Vitiello V, Lee SL, Cundy TP, Yang GZ. Emerging robotic platforms for minimally invasive surgery. IEEE Rev Biomed Eng 2013; 6: 111-126

50. Philip W, Simon S, Samuel K. Transcervical minimally invasive esophagectomy using da Vinci® $\mathrm{SP}^{\mathrm{TM}}$ Surgical System: a feasibility study in cadaveric model. Surg Endosc 2019; 33: 1683-1686

51. Shin WH, Kwon DS. Surgical robot system for single-port surgery with novel joint mechanism. IEEE Trans Biomed Eng 2013; 60(4): 937-944

52. Kaouk JH, Goel RK, Haber GP, Crouzet S, Stein RJ. Robotic single-port transumbilical surgery in humans: initial report. BJU Int 2009; 103(3): 366-369

53. Liu QQ, Kobayashi Y, Zhang B, Ye J, Inko E, Cao Y, Sekiguchi Y, Cao Q, Hashizume M, Fujie MG. Design of an Insertable Surgical Robot with multi-level endoscopic control for Single Port Access Surgery. 2013 IEEE International Conference on Robotics and Biomimetics (ROBIO). Shenzhen. 2013: 750-755

54. Sekiguchi Y, Kobayashi Y, Watanabe H, Tomono Y, Noguchi T, Takahashi Y, Toyoda K,Uemura M, Ieiri S, Ohdaira T, Tomikawa $\mathrm{M}$, Hashizume M, Fujie MG. In vivo experiments of a surgical 
robot with vision field control for single port endoscopic surgery. 2011 Annual International Conference of the IEEE Engineering in Medicine and Biology Society. Boston, MA. 2011: 7045-7048

55. Sekiguchi Y, Kobayashi Y, Tomono Y, Watanabe H, Toyada K, Konishi K, Tomikawa M, Ieiri S, Tanoue K, Hashizume M, Fujie MG. Development of a tool manipulator driven by a flexible shaft for single port endoscopic surgery. Int Conf Biomed Robotics and Biomechatronics, 2010: 120-125

56. Won Lee J, Arkoncel FR, Rha KH, Choi KH, Yu HS, Chae Y, Han WK. Urologic robot-assisted laparoendoscopic single-site surgery using a homemade single-port device: a single-center experience of 68 cases. J Endourol 2011; 25(9): 1481-1485

57. Han WK, Kim DS, Jeon HG, Jeong W, Oh CK, Choi KH, Lorenzo EI, Rha KH. Robot-assisted laparoendoscopic single-site surgery: partial nephrectomy for renal malignancy. Urology 2011; 77(3): 612-616

58. Piccigallo M, Scarfogliero U, Quaglia C, Petroni G, Valdastri P, Menciassi A, Dario P. Design of a novel bimanual robotic system for single-port laparoscopy. IEEE/ASME Trans Mech 2010; 15(6): $871-878$

59. Xu K, Goldman RE, Ding J, Allen PK, Fowler DL, Simaan N. System design of an insertable robotic effector platform for single port access (SPA) surgery. IEEE/RSJ Int Conf Intelligent Robots and Systems 2009: 5546-5552

60. Botezatu I, Marinescu R, Laptoiu D. Minimally invasivepercutaneous surgery - recent developments of the foot surgery techniques. J Med Life 2015; 8(Spec Issue): 87-93

61. Kobayashi Y, Hamano R, Watanabe H, Koike T, Hong J, Toyoda K, Uemura M, Ieiri S, Tomikawa M, Ohdaira T, Hashizume M, Fujie MG. Preliminary in vivo evaluation of a needle insertion manipulator for central venous catheterization. Robomech J 2014; 1(18): 1-7

62. Hungr N, Troccaz J, Zemiti N, Tripodi N. Design of an ultrasoundguided robotic brachytherapy needle-insertion system. Proc 31st Ann Int Conf IEEE Eng Med Biol Soc 2009: 250-253

63. Simone C, Okamura AM. Modeling of needle insertion forces for robot-assisted percutaneous therapy. Proc Int Conf Robotics and Automation 2002: 2085-2091

64. Lumsden AB, Anaya-Ayala JE, Birnbaum I, Davies MG, Bismuth J, Cheema ZF, El Sayed HF, Seethamraju H, Loebe M, Valderrabano M. Robot-assisted stenting of a high-grade anastomotic pulmonary artery stenosis following single lung transplantation. J Endovasc Ther 2010; 17(5): 612-616

65. Yang Y, Tan UX, McMillan A, Gullapalli R, Desai JP. Design and implementation of a pneumatically-actuated robot for breast biopsy under continuous MRI. Proc IEEE Int Conf Robot Autom 2011: 674-679

66. Taillant E, Avila-Vilchis J, Allegrini C, Bricault I, Cinquin P. CT and MR compatible light puncture robot: architectural design and first experiments. Proc Mid Image Comput Comput-Assisted Interv 2004; 3217: 145-152

67. Abolhassani N, Patel R, Moallem M. Needle insertion into soft tissue: a survey. Med Eng Phys 2007; 29(4): 413-431

68. Zemiti N, Bricault I, Fouard C, Sanchez B, Cinquin P.LPR: a CT and MR-compatible puncture robot to enhance accuracy and safety of image-guided interventions. IEEE/ASME Trans Mech 2008; 13 (3): $306-315$
69. Masamune K, Fichtinger G, Patriciu A, Susil RC, Taylor RH, Kavoussi LR, Anderson JH, Sakuma I, Dohi T, Stoianovici D. System for robotically assisted percutaneous procedures with computed tomography guidance. Comput Aided Surg 2001; 6(6): 370-383

70. Tsekos NV, Khanicheh A, Christoforou E, Mavroidis C. Magnetic resonance-compatible robotic and mechatronics systems for image-guided interventions and rehabilitation: a review study. Annu Rev Biomed Eng 2007; 9(1): 351-387

71. Kaiser WA, Fischer H, Vagner J, Selig M. Robotic system for biopsy and therapy of breast lesions in a high-field whole-body magnetic resonance tomography unit. Invest Radiol 2000; 35(8): 513-519

72. Masamune K, Kobayashi E, Masutani Y, Suzuki M, Dohi T, Iseki H, Takakura K. Development of an MRI-compatible needle insertion manipulator for stereotactic neurosurgery. J Image Guid Surg 1995; 1(4): 242-248

73. Jiang G, Luo M, Bai K, Chen S. A precise positioning method for a puncture robot based on a PSO-optimized BP neural network algorithm. Appl Sci (Basel) 2017; 7(10): 969

74. Chen Y, Godage IS, Sengupta S, Liu CL, Weaver KD, Barth EJ, Webster RJ. An MRI-compatible robot for intracerebral hemorrhage removal. Proc Design of Medical Devices Conf 2017: 1-2

75. Willekens K, Gijbels A, Schoevaerdts L, Esteveny L, Janssens T, Jonckx B, Feyen JH, Meers C, Reynaerts D, Vander Poorten E, Stalmans $\mathrm{P}$. Robot-assisted retinal vein cannulation in an in vivo porcine retinal vein occlusion model. Acta Ophthalmol 2017; 95 (3): $270-275$

76. Shahriari N, Heerink W, van Katwijk T, Hekman E, Oudkerk M, Misra S. Computed tomography (CT)-compatible remote center of motion needle steering robot: fusing CT images and electromagnetic sensor data. Med Eng Phys 2017; 45: 71-77

77. Yang C, Xie Y, Liu S, Sun D. Force modeling, identification, and feedback control of robot-assisted needle insertion: a survey of the literature. Sensors (Basel) 2018; 18(2): 561

78. Kaalep A, Sera T, Oyen W, Krause BJ, Chiti A, Liu Y, Boellaard R. EANM/EARL FDG-PET/CT accreditation-summary results from the first 200 accredited imaging systems. Eur J Nucl Med Mol Imaging 2018; 45(3): 412-422

79. Ben-David E, Shochat M, Roth I, Nissenbaum I, Sosna J, Goldberg $\mathrm{SN}$. Evaluation of a CT-guided robotic system for precise percutaneous needle insertion. J Vasc Interv Radiol 2018; 29 (10): 1440-1446

80. Moreira P, van de Steeg G, Krabben T, Zandman J, Heckman EEG, van der Heijden F, Borra R, Misra S. The MIRIAM robot: a novel robotic system for MR-guided needle insertion in the prostate. $\mathrm{J}$ Med Robot Res 2017; 2(4): 1750006

81. Kim D, Kobayashi E, Dohi T, Sakuma I. A new, compact MRcompatible surgical manipulator for minimally invasive liver surgery. Proc Med Image Comput Comput-Assisted Intervention 2002; 2488: 164-169

82. Moser R, Gassert R, Burdet E, Sache L, Woodtli HR, Erni J, Maeder W, Bleuler H. An MR-compatible robot technology. Proc IEEE Int Conf Robotics Automation 2003: 670-75

83. Koseki Y, Kikinis R, Jolesz F, Chinzei K. Precise evaluation of positioning repeatability of MR-compatible manipulator inside MRI. Proc Med Image Comput Comput-Assisted Intervention 
2004: 192-99

84. Takahashi N, Tada M, Ueda J, Matsumoto Y, Ogasawara T. An optical 6-axis force sensor for brain function analysis using fMRI. Proc IEEE Int Conf Sensors 2003: 253-58

85. Kataoka H, Washio T, Audette M, Mizuhara K. A model for relations between needle deflection, force, and thickness on needle penetration. Proc Med Image Comput Comput Assist Interv 2001: 966-74

86. Kataoka H, Washio T, Chinzei K, Mizuhara K, Simone C, Okamura AM. Measurement of the tip and friction force acting on a needle during penetration. Proc Med Image Comput Comput Assist Interv 2002: 216-23

87. Abolhassani N, Patel R, Moallem M. Trajectory generation for robotic needle insertion in soft issue. IEEE Int Conf of the EMBS 2004: 2730-2733

88. Seifabadi R, Iordachita I, Fichtinger G. Design of a teleoperated needle steering system for MRI-guided prostate interventions. Proc IEEE RAS EMBS Int Conf Biomed Robot Biomechatron 2012: 793-798

89. Webster RJ, Memisevic J, Okamura AM. Design considerations for robotic needle steering. IEEE Int Conf Robot Autom 2005: 3599-3605

90. Kobayashi Y, Okamoto J, Fujie MG. Position control of needle tip based on physical properties of liver and force sensor. J Robot Mechatron 2006; 18(2): 167-176

91. Watanabe H, Kobayashi Y, Hoshi T, Kawamura K, Fujie MG, Hashizume M. Integrated system for RFA therapy with biomechanical simulation and needle insertion robot. 2009 IEEE/SICE International Symposium on System Integration (SII). Tokyo. 2009: 54-59

92. Kobayashi Y, Kato A, Watanabe H, Hoshi T, Kawamura K, Fujie MG. Modeling of viscoelastic and nonlinear material properties of liver tissue using fractional calculations. J Biomech Sci Eng 2012; 7(2): 177-187

93. Kobayashi Y, Suzuki M, Kato A, Hatano M, Konishi K, Hashizume M, Fujie MG. Enhanced targeting in breast tissue using a robotic tissue preloading-based needle insertion system. IEEE Trans Robot 2012; 28(3): 710-722

94. Kobayashi Y, Hong J, Hamano R, Okada K, Fujie MG, Hashizume M. Development of a needle insertion manipulator for central venous catheterization. Int J Med Robot 2012; 8(1): 34-44

95. Ten Tusscher KH, Noble D, Noble PJ, Panfilov AV. A model for human ventricular tissue. Am J Physiol Heart Circ Physiol 2004; 286(4): H1573-H1589

96. O’Hara T, Virág L, Varró A, Rudy Y. Simulation of the undiseased human cardiac ventricular action potential: model formulation and experimental validation. PLOS Comput Biol 2011; 7(5): e1002061

97. O’Leary MD, Simone C, Washio T, Yoshinaka K, Okamura AM. Robotic needle insertion: effect of friction and needle geometry. Proc IEEE Int Conf Robot Autom 2003: 1774-1779

98. Schneider CM, Okamura A, Fichtinger G. A robotic system for transrectal needle insertion into prostate with integrated ultrasound. Proc IEEE Int Conf Robot Autom 2004: 365-370

99. DiMaio SP, Salcudean SE. Needle insertion modeling and simulation. IEEE Trans Robot Autom 2003; 19(5): 864-875

100. Ebrahimi R, Okazawa S, Rohling R, Salcudean EE. Hand-held steerable needle device. MICCAI 2003; 2879: 223-229

101. Hiemenz L, Lisky A, Schmalbrock P. Puncture mechanics for the insertion of an epidural needle. 21st Annual Meeting of the American Society of Biomechanics 1997

102. Abdalla EK, Vauthey JN, Ellis LM, Ellis V, Pollock R, Broglio KR, Hess K, Curley SA. Recurrence and outcomes following hepatic resection, radiofrequency ablation, and combined resection/ablation for colorectal liver metastases. Ann Surg 2004; 239 (6): 818-827

103. Tsukune M, Kobayashi Y, Miyashita T, Fujie MG. Breast tumor phantom utilizing heat coagulation to mimic nonlinear elasticity. 27th Int Congr and Exhib on Computer Assisted Radiology and Surgery 2013: PO12-00050

104. Yuen SG, Novotny PM, Howe RD. Quasiperiodic predictive filtering for robot-assisted beating heart surgery. IEEE Int Conf Robot Autom 2008: 3875-3880

105. Aaronson OS, Tulipan NB, Cywes R, Sundell HW. Robot-assisted endoscopic intrauterine myelomeningocele repair: a feasibility study. Pediatr Neurosurg 2002; 36(2): 85-89

106. Hoshi T, Kobayashi Y, Kawamura K, Fujie MG. Developing an intraoperative methodology using the finite element method and the extended Kalman filter to identify the material parameters of an organ model. Proc 29th Annual Int Conf of IEEE Eng in Med Biol Soc 2007: 469-474

107. Lu H, Yang Y, Lin X, Shi P, Shen Y. Low-invasive cell injection based on rotational microrobot. J Advanced Biosystems 2019: 1800274

108. Lu H, Zhang M, Yang Y, Huang Q, Fukuda T, Wang Z, Shen Y. A bioinspired multilegged soft millirobot that functions in both dry and wet conditions. Nat Commun 2018; 9(1): 3944

109. Miriyev A, Stack K, Lipson H. Soft material for soft actuators. Nat Commun 2017; 8(1): 596

110. Bartlett NW, Tolley MT, Overvelde JTB, Weaver JC, Mosadegh B, Bertoldi K, Whitesides GM, Wood RJ. SOFT ROBOTICS. A 3Dprinted, functionally graded soft robot powered by combustion. Science 2015; 349(6244): 161-165 